\title{
Development of Recommendations to Continue Anticoagulation with One of the Two Types of Oral Anticoagulants Based on the Identification of Patients' Preference
} \author{
Jürgen Koscielny, $\mathrm{MD}^{7}$ Gregory Y. H. Lip, $\mathrm{MD}^{8}$ \\ 1 Department of Clinical Pharmacology, Medical Faculty Mannheim, \\ Ruprecht-Karls University Heidelberg, Mannheim, Germany \\ ${ }^{2}$ Central Institute for Mental Health, Medical Faculty Mannheim, \\ Ruprecht-Karls University Heidelberg, Mannheim, Germany \\ ${ }^{3}$ Department of Biometry and Statistics, Medical Faculty Mannheim, \\ Ruprecht-Karls University Heidelberg, Mannheim, Germany \\ ${ }^{4}$ Center for Thrombosis and Hemostasis, Mainz, Germany \\ ${ }^{5}$ German Center for Cardiovascular Research (DZHK), Mainz, Germany \\ ${ }^{6}$ Division of Angiology, Department of Medicine III, University Hospital \\ Carl Gustav Carus Dresden Center for Vascular Medicine, \\ Dresden, Germany \\ ${ }^{7}$ Institute for Transfusion Medicine, Charité-University Hospital, \\ Berlin, Germany \\ 8 University of Birmingham Centre for Cardiovascular Sciences City \\ Hospital Birmingham, Birmingham, United Kingdom
}

Shabnam Zolfaghari, MSc ${ }^{1}$ Job Harenberg, MD ${ }^{1}$ Lutz Frölich, MD ${ }^{2}$ Christel Weiss, PhD $^{3}$ Martin Wehling, MD ${ }^{1}$ Philip Wild, $\mathrm{MD}^{4}$ Jürgen Prochaska, $\mathrm{MD}^{5}$ Jan Beyer-Westendorf, MD

Address for correspondence Job Harenberg, MD, Clinical Pharmacology Manheim, Medical Faculty Mannheim, Ruprecht-Karls University Heidelberg, Maybachstr. 14, 68169 Mannheim, Germany (e-mail: job.harenberg@medma.uni-heidelberg.de).

\section{Keywords}

- anticoagulation

- vitamin K antagonist

- new oral anticoagulant

- preference

- questionnaire

- score

- recommendation
Patients with indication for anticoagulation may prefer treatment with a vitamin $\mathrm{K}$ antagonist (VKA) or non-vitamin $\mathrm{K}$ antagonist oral anticoagulant (NOAC). A questionnaire may help to identify the preference of patients for one of the two types of oral anticoagulants and to develop a score for the recommendation to continue or to change the anticoagulant. A score was developed using a questionnaire containing biographic data and eight statements on attitudes on anticoagulation and was derived to trigger continuation or change the type of anticoagulant by defining ranges of terms and weighting of the significant statements identified by logistic regression analysis. Participating patients received either anticoagulation with VKA (group $1, n=690$ ), were transferred from VKA to NOAC (group 2, $n=158$ ), received NOAC de novo (group $3, n=137$ ) or were transferred from NOAC to VKA (group $4, n=19$ ). Four statements were significantly ( $p$ values between 0.0347 and $<0.0001$ ) associated with recommendations to maintain or to change the type of anticoagulant for patients in groups 1 , 2 , or 3 with predictive values of $c=0.83$ between groups 1 and 2 and $c=0.71$ between groups 1 and 3 . From the total number of replies to the statements a score of three grades and two strengths $(A=$ strong, $B=$ moderate) was derived for the recommendations. This tool supports recommendations as to continue or to change the presently used type of oral anticoagulant based on the identification of patients' preferences.
Issue Theme Anticoagulant Therapy: Present and Future; Guest Editor: Job Harenberg, MD. published online

February 19, 2015
DOI http://dx.doi.org/ 10.1055/s-0035-1546467. ISSN 0094-6176.
Copyright @ 2015 by Thieme Medical Publishers, Inc., 333 Seventh Avenue, New York, NY 10001, USA. Tel: +1(212) 584-4662.

\section{License terms}

()(1) $\Theta \circledast$ 
Patients with acute thromboembolic events and those at risk for developing these events as complications of underlying diseases require immediate anticoagulation (AC); traditionally, treatment is initiated by rapidly acting anticoagulants such as heparin or low-molecular-weight heparin followed by overlapping initiation of oral anticoagulant therapy with vitamin $\mathrm{K}$ antagonist (VKA). ${ }^{1}$ To address several limitations of therapy with heparins and VKA, non-vitamin $\mathrm{K}$ antagonist oral anticoagulants (NOAC) have been developed. By now, the oral direct thrombin inhibitor dabigatran and the oral direct factor Xa inhibitors rivaroxaban, apixaban, and edoxaban have obtained approval for the prevention and treatment of thromboembolic diseases. ${ }^{2}$

After over 50 years of conventional anticoagulants with little freedom of choice, patients may now be involved in the decision of choosing between two major types of anticoagulants, VKA or NOAC. Inclusion of patients into this decision process may improve the underuse ${ }^{3}$ and adherence issues ${ }^{4}$ inherent to all chronic oral treatments. The unwillingness of patients to take warfarin was reported as a major contributor to under treatment and nonadherence. ${ }^{5}$ The introduction of a computerized decision-making tool including patients' preferences resulted in a better information on balanced benefits and harms of anticoagulant therapy than conventional paper-based information systems. ${ }^{6}$ Similarly, the inclusion of patients' preferences also resulted in improved acceptance and adherence to therapeutic decisions for other diseases and medications. ${ }^{7}$

The Guidelines of the European Society of Cardiology, ${ }^{8}$ the American College of Cardiology Foundation (ACCF) American heart association (AHA), ${ }^{9}$ Heart Rhythm Society (HRS), American College of Chest Physicians (ACCP), ${ }^{10}$ and the National Institute for Health and Care Excellence ${ }^{11}$ all mention the importance of patients' values and preferences for VKA or NOAC in the treatment decision. A good physician-patient relationship is pivotal for patients' compliance and thus, the quality and effectiveness of therapies. ${ }^{12}$ To identify preferences of patients in a therapeutic decision process questionnaires have been developed and validated. ${ }^{13}$ Studies have shown that some patients are even willing to partially pay for a NOAC out of their pockets as they were strongly preferring a NOAC over VKA. ${ }^{14}$ Studies described the willingness of patients to change AC from VKA to NOAC ${ }^{15,16}$ and the high motivation of patients to participate in clinical trials with NOAC. ${ }^{17}$ To facilitate the involvement of patients in the decision process a questionnaire for the identification of the patients' preferences for choosing NOAC instead of VKA was developed based on published techniques. ${ }^{18}$ Preliminary data have been reported earlier describing the utility of this questionnaire for the choice of the one of the two types of anticoagulants. ${ }^{15}$ Such an approach has to guide decisions on four related options: (1) despite the availability of NOAC patients may prefer continue therapy with VKA, (2) switch AC from VKA to NOAC, (3) start AC de novo with NOAC, or (4) switch from NOAC to VKA.

Previously we reported on the willingness of patients to change AC from VKA to NOAC using the following questionnaires: the "Freiburger Personality Inventory" in its revised form FPI-R, ${ }^{19}$ the "State-Trait Anxiety Inventory-Trait,"20,21 the short form health survey, ${ }^{22}$ and the "questionnaire on the attitudes of patients for anticoagulant therapy."15 Logistic regression analysis identified several statements of the questionnaires on attitudes and the personality trait extraversions as important predictors of continuing AC with VKA or changing $A C$ to NOAC with a probability of $98 \%{ }^{15}$

In this study, we investigate these personality traits in patients who presented after a switch of anticoagulant therapy to NOAC or initiation of therapy with NOAC de novo. These preceding treatment decisions were correlated with the patients' preferences for the type of anticoagulant-VKA or NOAC-as determined in the questionnaire; accordingly, recommendations to continue or to change type of anticoagulant based on patients' replies to the statements were derived.

\section{Methods}

\section{Patients and Methods}

Patients with the following inclusion criteria were included into the prospective multicentric study: (1) either current therapy with VKA (group 1), or earlier change of AC from VKA to NOAC (group 2), or treatment with NOAC de novo without previous therapy with another type of anticoagulant (group 3 ), or earlier change of AC from NOAC to VKA (group 4); (2) age above 18 years; (3) informed consent in written form or by accepting statements on the related Web site. Exclusion criteria were: (1) participation of patients with mental diseases causing inability to reply to the questions themselves without help of others; and (2) no AC with VKA or NOAC.

Patients with oral anticoagulant therapy were recruited through a network consisting of specialized institutions for AC (see below), through advertisements in daily newspapers and through an internet platform. They had to complete a questionnaire aiming to identify the preference of patients for one of the two types of oral anticoagulants VKA or NOAC; several statements and questions address the satisfaction with the present anticoagulant, wishes for improvement of their anticoagulant therapy and document some biographic data. The questionnaire was available either as paper form or online through the homepage www.blutverduennung.unihd.de. The patients were excluded from the evaluation if they did not reply to two or more statements in the paper form. The online form could not be submitted if a question remained unanswered. Participants were instructed to complete the questionnaire.

The network included outpatient care units at the universities of Mannheim, Mainz, Berlin, Dresden, and several practitioners specialized in AC in Germany. An internet platform consisted of a specific homepage, information on the study was disseminated in scientific journals, local, regional, and national German newspapers, advertisements at conferences, on the Web sites of International SelfMonitoring Association of oral Anticoagulated Patients and of the German Society of Thrombosis and Haemostasis Research. The study was approved by the ethics committees of the universities of Heidelberg in Mannheim, Mainz, and Dresden. The other participating centers accepted the principal ethics vote of Heidelberg. Patients gave written informed 
consent before participation if they used the paper form of the questionnaire; or by confirming reading and understanding of the informed consent for the Internet version.

\section{Biographic Data and Questionnaire}

\section{Biographic Data}

The following parameters were documented for all patients: gender, age, school graduation, indication for AC (atrial fibrillation, venous thrombosis, pulmonary embolism, artificial heart valve replacement, myocardial infarction, ischemic stroke, peripheral arterial disease, other disease, no $\mathrm{AC}$ ), and duration of AC with the present anticoagulant. Patients were invited to give additional information on their diseases in an open field. Self-monitoring was documented for patients of groups 1 and 4 and intake and daily dose of the specific NOAC for patients of groups 2 and 3. Patients of group 3 did not receive the statement 3 in the questionnaire (if the prothrombin time or international normalized ratio [INR] was difficult to adjust).

\section{Questionnaire}

We used the questionnaire developed for identification of the willingness to change anticoagulants from VKA to NOAC ${ }^{15}$ and analyzed the differences of the statements in the questionnaire between three groups of patients (see above). The fourth group of patients was not included into this part of the evaluation due to the low number of participants. Patients in group 2 had previously changed AC from VKA to NOAC and therefore the results of the statements could be interpreted to detail conditions of their preference for NOAC. Since the initial studies several NOAC were approved for atrial fibrillation (AF) and venous thromboembolism (VTE) and patients with NOAC de novo were also included (group 3 ) were included into the study. Change of therapy from NOAC to VKA (group 4) was included for completeness, but this condition was rarely met.

The statements in the questionnaire were the following: statement 1 , I have had thoughts in the past of alternatives for AC; statement 2, I hope for a better quality of life with a new anticoagulant; statement 3 , I have had low stability of the prothrombin time or international normalized ratio (INR); statement 4, I have a wish of a lack of routine monitoring for dose adjustment of anticoagulant therapy; statement 5, I have relevance of the practitioners opinion for type of anticoagulant; statement 6, I have no scepticism for new drugs; statement 7, My judgement of own personality trait is for extraversion; and statement 8 , I have satisfaction with current anticoagulant. ${ }^{15}$

Patients had to decide on the intensity of agreement or disagreement with the statements of the items by choosing a number between 0 and 10 . Numbers between 0 and 5 indicated different intensities of disagreement with the statement, and numbers between 6 and 10 indicated different intensities of agreement with the statement.

\section{Electronic Documentation of the Questionnaire}

The questionnaire on the internet was created using the web-based software Evaluation System (EvaSys, Electric Paper Ltd., London, United Kingdom), which was initially developed for scientific evaluations of educational events and seminars. The evaluation process with EvaSys is visualized in several successive phases. ${ }^{23,24}$ First, the design of the questionnaire is created. Second, the type of answers from various formats as single or multiple choice, open question or scale is selected. The scales can be classified as nominal scale, ordinal scale, interval scale, and ratio scale. EvaSys generates a PDF file or an HTML file including patients' data and simple corresponding statistical measures such as frequencies or mean values. To ensure that only qualifying persons use the questionnaire, EvaSys individual transaction numbers (TANs) have to be created. Upon reading the PDF of the informed consent followed by the agreement of a person to participate in questionnaire, a TAN was sent with a link from the homepage to the participant. In the third phase, the data of the completed questionnaires are collected by EvaSys and automatically transferred into an Excel database spreadsheet. In the fourth phase the raw data are exported for analysis in statistical programs such as SAS (SAS Institute Inc., Cary, NC).

The data analysis in our study was performed with SAS statistical software release 9.3. The paper forms of the questionnaire were transferred into Excel (S.Z.). Documented data in Excel fundamentally simplify the work for SAS programmers because it imported the data into SAS for evaluation.

\section{Logistic Regression Analysis}

Multiple logistic regression analysis was performed to compare groups 1 and 2 as well as groups 1 and 3. Group 4 was not included into this analysis due to the small number of patients. In this analysis, significant and nonsignificant variables (statements 1 to 8 ) indicating group differences were identified. In addition regression parameters were available for each significant item. These parameters allowed estimating the probability that a patient belongs to group 1 or the other group ( 2 or 3 ). The significant items will be used later for the recommendation to continue or to change the type of anticoagulant.

The patients in group 3 have NOAC as an anticoagulant drug that are not required to have their prothrombin time or INR adjusted and do not have any experience with VKA. It is important to see if these patients are satisfied with NOAC or would like to change to VKA. Therefore on the basis of logistic regression analysis, we compared the patients in group 1 who take VKA with the patients in group 3 who do not have any experience with VKA. The significant items from this comparison will be used for patients who take NOAC de novo as an anticoagulant.

\section{Calculation of Terms and Intervals}

The value for the reply by the patient on the scale (Sn) will be multiplied with the estimate value $(W)$ which is calculated by regression analysis $\left(W_{S n}\right)$. Then, all values are added. The calculated sum is called "term" (Eq. 1).

$$
\begin{aligned}
& \text { Term }=\left(\mathrm{S} 1 \times W_{\mathrm{S} 1}\right)+\left(\mathrm{S} 2 \times W_{\mathrm{S} 2}\right)+\left(\mathrm{S} 3 \times W_{\mathrm{S} 3}\right)+(\mathrm{S} 4 \times \\
& \left.W_{\mathrm{S} 4}\right)+\ldots \ldots . .+\mathrm{Sn} \times W_{\mathrm{Sn}}(\text { Eq. } 1)
\end{aligned}
$$


An interval and cut off values of the categories were determined as proposals to change (y-axis) or to continue AC with the present type of anticoagulant (x-axis). The interval was calculated by using the exponential function. This equation ensured that in each case a probability is ascertained which lies between 0 and 1 (Eq. 2).

$$
\mathrm{Y}=\exp (\text { Term }) /(\exp [\text { Term }]+1)(\text { Eq. 2) }
$$

According to the Eq. 3 and the calculated "Y" value, the sum of $(\mathrm{X})$ will be calculated by using the linear function.

$$
X=1-Y(\text { Eq. } 3)
$$

Such a function is presented graphically as a straight line. $(\mathrm{X})$ and $(\mathrm{Y})$ each will get a value between " 0 " and " 1 " based on the Eq. 3 and the decisions on the recommendations for therapy are based on the calculated $(\mathrm{X})$ and $(\mathrm{Y})$ values supplemented by Eq. 2 and Eq. 3. A change of AC therapy will be calculated according to the Eq. 2 as follows:

Change type of $A C=\exp ($ Term $) /(\exp [$ Term $]+1)($ Eq. 4)

The recommendation to continue or change therapy with type of anticoagulant was calculated according to the Eq. 3:

Continue type of $A C=1-$ change type of $A C$ (Eq. 5)

These mathematical supplements were used to define the recommendation. Thereby, replies of patients will fall into the highest range of terms of $>90 \%$, into the range of terms between 55 and $90 \%$ and into the range of terms between 45 and $55 \%$.

\section{Definition of a Score by Strength of the Recommendation Grading System}

To develop a score for patients according to a recommendation to continue or change therapy with the presently used anticoagulant on the basis of the results of the significant statements by groups, three grades (1-3) and two strengths
(A and $B$ ) were defined. The three grades of recommendations were as follows: (1) to continue anticoagulant therapy with strong or moderate strength (1A and $1 \mathrm{~B}),(2)$ no recommendation for changing or continuing the present type of anticoagulant; and (3) to change present type of anticoagulant with strong or moderate strength of recommendation (3A and 3B). The limits for these recommendations were as follows: recommendation $1 \mathrm{~A}$, values of over $90 \%$ on x-axis; recommendation $1 \mathrm{~B}$, values from 55 to $90 \%$ on $\mathrm{x}$-axis; recommendation 2, values between 45 and $55 \%$ on $\mathrm{y}$ - and $\mathrm{x}$-axis; recommendation $3 \mathrm{~B}$, values from 55 to $90 \%$ on $\mathrm{y}$-axis, and recommendation $3 \mathrm{~A}$, values from 90 to $100 \%$ on $y$-axis. The concept of the five different recommendations is shown in - Fig. 1.

\section{Statistical Analysis}

Descriptive statistics are given as mean and standard deviation (SD) for continuous variables and as numbers and percentages for categorical variables. In this work, the statistical analysis was done using SAS release 9.3. Each question was analyzed with a different statistical test depending on the particular shape of the response (dichotomous response, scale-choice or multiple-choice, open-ended question). The chi-square or Fisher exact test was used to compare the four groups regarding biographical data such as gender or diseases of the patients. The Kruskal-Wallis test was used for the comparison of an ordinal scaled variable or a quantitative variable not normally distributed. ${ }^{25}$ For comparisons of age and graduation of two groups, the $t$-test or Mann-Whitney U-test was performed. Logistic regression analysis of the replies for the eight items was performed comparing data of groups 1 and 2; groups 1 and 3; and group 3. P-values $<0.05$ were considered as statistically significant.

\section{Results}

\section{Biographic Data}

Between February 1, 2013, to January 1, 2014, a total of 1,001 patients (633 males, mean $\pm \mathrm{SD}, 66.9 \pm 10.9$ years; 368 females, $63.2 \pm 15.3$ years) were included into the study

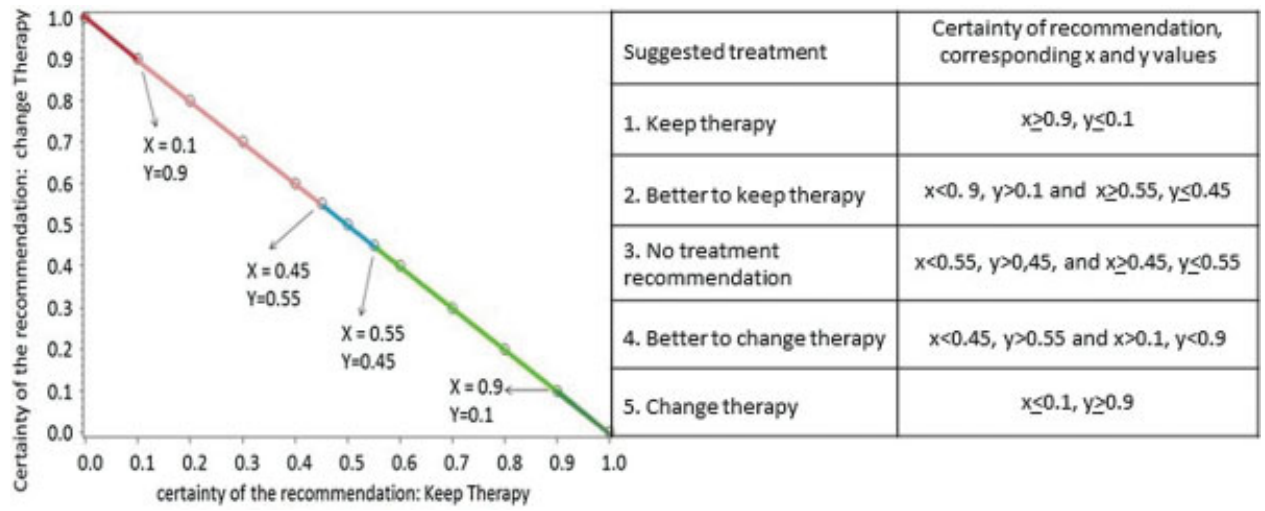

Fig. 1 Description of the grades/certainties of recommendation in relation to the suggested change (y-axis) or keep therapy recommendations (x-axis), and the certainty of these recommendations. Dark red and dark green color, strong grade of recommendation; light red and light green, moderate grade of recommendation; and blue color, no recommendation. 
( $p=0.0056$ for differences of gender and $p=0.3920$ for differences of age between groups, - Table 1). Overall, 690 patients were treated with VKA (group 1), 155 patients had changed AC from VKA to NOAC (group 2), 137 were treated by NOAC de novo (group 3), and 19 patients changed therapy from NOAC to VKA. The patients in group 4 switched AC from NOAC to VKA due to complications such as hair loss after 9 months of treatment or general discomfort, due to fear of side effects on NOAC, or nonreimbursement by the health insurer. Due to the low number of patients, group 4 is not included in the analysis.

Persons with higher degrees of school education were in groups 2 and 3 compared with group 1 (for $p$-values see - Table 1). About $30 \%$ of the patients with VKA performed self-monitoring of INR. The most frequent indication for AC was AF in groups 2 and 3 compared with group 1 . All patients with artificial heart valve replacement received VKA (group 1). There were no differences between groups for patients with VTE. The results of biographic data are given in - Table 1.

\section{Statements of the Questionnaire}

A descriptive analysis was performed for four groups of patients. For each group, minimum, maximum, median, mean value, and SD of the variables are shown in - Table 2. Results are described below in detail:

Statement 1: Patients of group 3 had fewer thoughts on AC (mean $\pm \mathrm{SD}: 4.44 \pm 4.26$ ) in the past compared with patients of group 1 (4.58 \pm 4.31$)$ and of group $2(5.25 \pm 4.23)$ with a $p$-value of 0.0499 . The differences can be attributed to the higher values of group 2 .
Statement 2: Mean values of group 1 were lower than groups 2 and 3 because patients do not expect that changing therapy from VKA to NOAC would improve quality of life as they are apparently content with the current treatment or because they may have constraints with the NOAC. Mean values of group 2 were higher because patients had expected more that changing therapy from VKA to NOAC would improve quality of life. More favorable replies of patients in group 3 over those from group 1 (NOAC naive patients) (-Table 2) may indicate that they have a better quality of life compared with patients on therapy with VKA.

Statement 3: Patients documented that the INR and was not difficult to adjust with mean values ( \pm SD) of $2.07 \pm 3.13$ in groups 1 and 4 , and $2.21 \pm 2.62$ in group 2 (-Table 2). Patients in group 2 had higher values $(4.83 \pm 4.07)$ indicating difficulties to adjust the INR before changing AC to NOAC. Patients of group 3, who had no experience with warfarin, did not receive statement 3 . Values were significantly different between groups (-Table 2, $p=0.0001$ ).

Statement 4: The patients of groups 1 and 4 assigned low values to this statement, because blood sampling does not represent a limitation to adjust the INR. In contrast, patients of groups 2 and 3 produced higher values to this statement (mean \pm SD $7.44 \pm 3.49$ and $7.21 \pm 3.78$ ) (-Table 2). The differences between groups were significant $(p=0.0002)$. Interestingly, this statement was not assigned significance in the logistic regression analysis.

Statement 5: The recommendation of the physician was more important for patients of group 3 compared with the other groups but values were not significantly different ( - Table 2 ).

Table 1 Biographic data of the patient groups

\begin{tabular}{|c|c|c|c|c|c|c|c|c|}
\hline \multicolumn{2}{|l|}{$\begin{array}{l}\text { Biographic } \\
\text { data }\end{array}$} & \multirow{2}{*}{$\begin{array}{l}\text { Group } \\
n\end{array}$} & \multirow{2}{*}{$\begin{array}{l}1 \\
690\end{array}$} & \multirow{2}{*}{$\begin{array}{l}2 \\
155\end{array}$} & \multirow{2}{*}{$\begin{array}{l}3 \\
137\end{array}$} & \multirow{2}{*}{$\begin{array}{l}4 \\
19\end{array}$} & \multirow{2}{*}{$\begin{array}{l}\text { Sum } \\
1,001\end{array}$} & \multirow[t]{2}{*}{$p$ Value } \\
\hline All patients & & & & & & & & \\
\hline Gender & Male, female & $n \%$ & $\begin{array}{l}447 / 243 \\
64.8 / 35.2\end{array}$ & $\begin{array}{l}92 / 63 \\
59.3 / 40.7\end{array}$ & $\begin{array}{l}89 / 48 \\
65.0 / 35.0\end{array}$ & $\begin{array}{l}5 / 14 \\
26.3 / 73.7\end{array}$ & $633 / 368$ & 0.0056 \\
\hline Age & Mean, SD & $y$ & $\begin{array}{l}67.4 \pm \\
11.9\end{array}$ & $\begin{array}{l}66.3 \pm \\
12.5\end{array}$ & $\begin{array}{l}65.7 \pm \\
11.1\end{array}$ & $\begin{array}{l}67.4 \pm \\
12.2\end{array}$ & $\begin{array}{l}66.97 \pm \\
11.9\end{array}$ & 0.3920 \\
\hline \multirow{4}{*}{$\begin{array}{l}\text { School } \\
\text { graduation }\end{array}$} & School certificate & $n / \%$ & $299 / 43.3$ & $48 / 31.0$ & $21 / 15.3$ & $5 / 26.3$ & 373 & $<0.0001$ \\
\hline & $\begin{array}{l}\text { High school } \\
\text { certificate }\end{array}$ & $n / \%$ & $200 / 29.0$ & $51 / 32.9$ & $62 / 45.3$ & $11 / 57.9$ & 324 & 0.0002 \\
\hline & Apprenticeship & $n / \%$ & $89 / 12.9$ & $21 / 13.6$ & $17 / 12.4$ & $2 / 10.5$ & 129 & 0.9803 \\
\hline & University degree & $n / \%$ & $98 / 14.2$ & $35 / 22.6$ & $37 / 27.0$ & $1 / 5.3$ & 171 & 0.0003 \\
\hline \multirow[t]{5}{*}{ Indication } & Atrial fibrillation & $n / \%$ & $363 / 52.6$ & $102 / 65.0$ & $101 / 17.5$ & $7 / 36.8$ & 573 & $<0.0001$ \\
\hline & $\begin{array}{l}\text { Heart valve } \\
\text { replacement }\end{array}$ & $n / \%$ & $107 / 15.5$ & $0 / 0$ & $0 / 0$ & $0 / 0$ & 107 & $<0.0001$ \\
\hline & Vessel operation & $n / \%$ & $43 / 6.2$ & $2 / 1.3$ & $1 / 0.7$ & $0 / 0$ & 46 & 0.0034 \\
\hline & Thromboembolism & $n / \%$ & $147 / 21.3$ & $44 / 28.4$ & $26 / 19.0$ & $7 / 36.8$ & 224 & 0.0758 \\
\hline & Other & $n / \%$ & $34 / 4.9$ & $8 / 5.2$ & $9 / 6.6$ & $0 / 0$ & 41 & 0.6420 \\
\hline Self-monitoring & & $n / \%$ & $261 / 98.9$ & $0 / 0$ & $0 / 0$ & $3 / 1.1$ & 264 & 0.0495 \\
\hline Duration & Mean, SD & mo & $87.1 \pm 83.0$ & $15.7 \pm 29.1$ & $8.8 \pm 6.4$ & $10.2 \pm 7.5$ & ne & $<0.0001$ \\
\hline
\end{tabular}

Abbreviation: Ne, not evaluated. 
Table 2 Descriptive statistics of the statements and p-values between the four groups (Kruskal-Wallis test)

\begin{tabular}{|c|c|c|c|c|c|c|c|}
\hline Group & $n$ & Min & Max & Median & Mean & SD & $P$ Value \\
\hline \multicolumn{8}{|c|}{ Statement 1} \\
\hline 1 & 690 & 0 & 10 & 5 & 4.58 & 4.31 & \multirow[t]{4}{*}{0.0499} \\
\hline 2 & 155 & 0 & 10 & 6 & 5.25 & 4.23 & \\
\hline 3 & 137 & 0 & 10 & 4 & 4.44 & 4.26 & \\
\hline 4 & 19 & 0 & 8 & 2 & 2.47 & 2.80 & \\
\hline \multicolumn{8}{|c|}{ Statement 2} \\
\hline 1 & 690 & 0 & 10 & 5 & 4.88 & 3.95 & \multirow[t]{4}{*}{0.0001} \\
\hline 2 & 155 & 0 & 10 & 9 & 7.94 & 2.70 & \\
\hline 3 & 137 & 0 & 10 & 9 & 7.26 & 3.58 & \\
\hline 4 & 19 & 0 & 10 & 8 & 6.63 & 3.27 & \\
\hline \multicolumn{8}{|c|}{ Statement 3} \\
\hline 1 & 690 & 0 & 10 & 0 & 2.07 & 3.13 & \multirow[t]{3}{*}{0.0001} \\
\hline 2 & 155 & 0 & 10 & 5 & 4.83 & 4.07 & \\
\hline 4 & 19 & 0 & 9 & 2 & 2.21 & 2.62 & \\
\hline \multicolumn{8}{|c|}{ Statement 4} \\
\hline 1 & 690 & 0 & 10 & 8 & 6.02 & 4.19 & \multirow[t]{4}{*}{0.0002} \\
\hline 2 & 155 & 0 & 10 & 9 & 7.44 & 3.49 & \\
\hline 3 & 137 & 0 & 10 & 10 & 7.21 & 3.78 & \\
\hline 4 & 19 & 0 & 10 & 5 & 4.74 & 4.09 & \\
\hline \multicolumn{8}{|c|}{ Statement 5} \\
\hline 1 & 690 & 0 & 10 & 9 & 6.86 & 3.81 & \multirow[t]{4}{*}{0.0609} \\
\hline 2 & 155 & 0 & 10 & 9 & 7.06 & 3.56 & \\
\hline 3 & 137 & 0 & 10 & 10 & 7.98 & 2.84 & \\
\hline 4 & 19 & 0 & 10 & 8 & 6.74 & 3.23 & \\
\hline \multicolumn{8}{|c|}{ Statement 6} \\
\hline 1 & 690 & 0 & 10 & 5 & 5.05 & 3.96 & \multirow[t]{4}{*}{0.0844} \\
\hline 2 & 155 & 0 & 10 & 4 & 4.17 & 3.74 & \\
\hline 3 & 137 & 0 & 10 & 5 & 4.83 & 3.91 & \\
\hline 4 & 19 & 0 & 10 & 5 & 5.63 & 3.77 & \\
\hline \multicolumn{8}{|c|}{ Statement 7} \\
\hline 1 & 690 & 0 & 10 & 9 & 8.07 & 2.60 & \multirow[t]{4}{*}{0.0003} \\
\hline 2 & 155 & 0 & 10 & 8 & 7.41 & 2.71 & \\
\hline 3 & 137 & 0 & 10 & 8 & 7.50 & 2.83 & \\
\hline 4 & 19 & 3 & 10 & 8 & 7.68 & 2.08 & \\
\hline \multicolumn{8}{|c|}{ Statement 8} \\
\hline 1 & 690 & 0 & 10 & 9 & 7.88 & 2.82 & \multirow[t]{3}{*}{0.0540} \\
\hline 2 & 155 & 0 & 10 & 10 & 8.77 & 1.92 & \\
\hline 3 & 137 & 0 & 10 & 9 & 8.15 & 2.56 & \\
\hline 4 & 19 & 4 & 10 & 9 & 8.21 & 1.93 & \\
\hline
\end{tabular}

Abbreviations: Max, maximum; Min, minimum; SD, standard deviation. 
Statement 6: A skeptical attitude of patients toward new drugs in general was not significantly different for the four groups in our study ( $\mathbf{- T a b l e ~} \mathbf{2}$ ). This was surprising because skepticism toward NOAC is suggested as a reason not to use them for $\mathrm{AC}$ at present (see discussion below).

Statement 7: From - Table 2 it can be seen that patients of group 1 were more extroverted $(8.07 \pm 2.60)$ compared with groups 2 and 3 . As described in the interpretation guide of the FPI-R, extroverted people can skip attitudes in a carefree manner are more talkative and quick witted. They are willing to take on tasks or even take the lead in joint operations. The introverted people are more profound and seriousness also dominates instead of impulsivity. The first may play a role for attitudes of patients preferring VKA and confirms previous investigations in a smaller number of patients. ${ }^{15}$ In contrast the latter attitudes may be more typical for patients preferring NOAC ( - Table 2).

Statement 8: Patients of group 2 are more satisfied with their anticoagulant treatment compared with the other groups $(p=0.0540)$. The patients in group 4 , who have changed AC from NOAC to VKA, were more satisfied with their current anticoagulant than patients of groups 1 and 3 probably due to side effects of NOAC (values see $\mathbf{-}$ Table $\mathbf{2}$ ).

\section{Regression Analysis}

Regression analysis of groups 1 and 2 showed significant differences for the following attitudes: statement 2 $(p<0.0001)$, statement $3 \quad(p<0.0001)$, statement 7 $(p=0.0003)$, and statement $8(p<0.0001)$. The regression analysis also yielded the relative weight $(W)$ for each statement as estimate value as follows: statement $2(W=0.2490)$, statement $3(W=0.2144)$, statement $7(W=0.1376)$, and statement $8(W=0.3274)$ ( - Table 3$)$. The receiver operating curves (ROC) of the comparison of group 1 versus group 2 showed an area under the curve with a $c$ value of 0.83 using the four statements indicating an $83 \%$ sensitivity to assign patients to groups 1 and 2 (- Fig. 2A).

The logistic regression was also performed between groups 1 and 3, which identified four statements as being
Table 3 Results of regression analyses for groups 1 and 2, and groups 1 versus 3 on significantly different statements (S), estimate values, and assignment of a positive or negative sign to each statement and $p$-values

\begin{tabular}{|c|c|c|}
\hline Statement & Estimate value & $p$ Value \\
\hline \multicolumn{2}{|l|}{ Group 1} & Group 1 vs. 2 \\
\hline S2 & 0.2490 & $<0.0001$ \\
\hline S3 & 0.2144 & $<0.0001$ \\
\hline S7 & -0.1376 & 0.0003 \\
\hline S8 & 0.3274 & $<0.0001$ \\
\hline \multicolumn{3}{|l|}{ Group 2} \\
\hline S2 & 0.2490 & $<0.0001$ \\
\hline S3 & 0.2144 & $<0.0001$ \\
\hline S7 & -0.1376 & 0.0003 \\
\hline S8 & 0.3274 & $<0.0001$ \\
\hline \multicolumn{2}{|l|}{ Group 3} & Group 1 vs. 3 \\
\hline S1 & -0.0622 & 0.0165 \\
\hline $\mathrm{S} 2$ & 0.2147 & $<0.0001$ \\
\hline 57 & -0.0978 & 0.0049 \\
\hline S8 & 0.0844 & 0.0347 \\
\hline
\end{tabular}

significant to distinguish patients: statement $1(p=0.0165)$, statement $3(p=0.0001)$, statement $7(p=0.0049)$, and statement $8(p=0.0347)$. The estimate values for the statements calculated by the regression analysis are given in -Table 3. The weight values for these statements are as follow: statement $1(W=0.622)$, statement $2(W=0.2147)$, statement $7(W=0.0978)$, and statement $8(W=0.0844)$ (-Table 3). ROC of the comparison of group 1 versus group 3 showed an area under the curve with a $c$ value of 0.71 ( - Fig. 2B) indicating that patients of group 3 can be identified with a sensitivity of $71 \%$ by the analysis of the four statements.
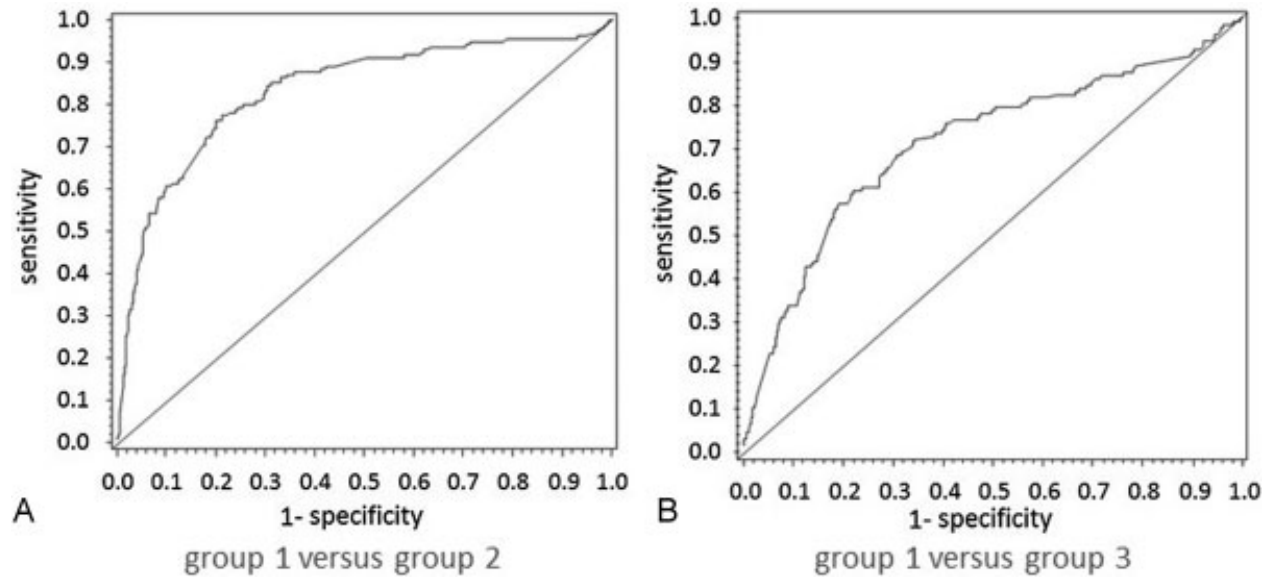

Fig. 2 (A) Receiver operating curve (ROC) for the comparison of group 1 versus group 2 . The area under the curve was $C=0.83$. The solid line corresponds to an area of 50\%. (B) ROC for the comparison of group 1 (VKA) versus group 3 (NOAC naive patients), $c=0.71$. NOAC, non-vitamin $\mathrm{K}$ antagonist oral anticoagulant; VKA; vitamin $\mathrm{K}$ antagonist. 


\section{Recommendations}

For the calculation of the treatment recommendation for patients in groups 1, 2, and 3 the term was calculated using the estimate values and the sign according to - Table 3 . The Eq. 1 and Eq. 2 were used to calculate the strength of the recommendation to continue or to change the type of anticoagulant. The limits were set at $>90 \%$ for a strong and at 55 to $90 \%$ for a moderate recommendation to continue or to change the present type of anticoagulant.

This number of terms range from -4.6500 to 4.6340 for group 1 , from -7.9080 to 1.3760 for group 2 , and from -2.9910 to 1.6000 for group 3. The terms were then allocated to the five categories of recommendations (continue [1] or change [3] type of anticoagulant or no recommendation for the use of type of anticoagulant [2]) and strong (A) or moderate (B) strength of recommendation. Data are shown as percent of the total number of replies per category of recommendation ( - Table 4 ).

The distribution of the recommendations is described below.

Group 1: In this study the distribution of recommendations to continue therapy was strong for $49 \%$ and moderate for $34 \%$ of patients. The recommendation to change the type of anticoagulant was strong in $3 \%$ and moderate in $10 \%$ of patients (-Fig 3a, - Table 4).

Group 2: In detail, a strong recommendation was made in our study for 95\%. Around 4\% of the 155 patients were recommended with moderate strength to continue therapy with NOAC. Only one patient received a moderate recommendation to convert AC from NOAC to VKA. According to the calculations no patient should change AC from NOAC to VKA with a strong recommendation (-Fig. $\mathbf{3 b}$, - Table 4 ).

For patients of group 3, the recommendations to continue or to change the type of anticoagulant were calculated using Eq. 1 and Eq. 2. About 7\% of the patients received a strong recommendation to continue therapy with NOAC. The term for these patients ranged from -2.9910 to -2.2873 . A moderate recommendation to continue or to change type of anticoagulant was given to 76 and $8 \%$ of the patients (certainty of recommendation 55-90\%) with terms of -2.1895 to -0.2368 and between 0.3028 and 1.3468 , respectively. A total of $9 \%$ of patients did not receive a recommendation for a specific type of anticoagulant. The term for these patients was between -0.1594 and 0.1962 . No patient received a strong recommendation to change $\mathrm{AC}$ with NOAC ( - Fig. 3c, - Table 4).

The higher number of moderate recommendations to change type of anticoagulant in group 3 compared with group 2 may be explained by the de novo NOAC treatment in contrast to patients of group 2 who actively decided to change therapy from VKA to NOAC.

\section{Subgroup Analyses}

A subgroup analysis of the data of group 1 showed that the distribution of the replies to the statements did not differ between patients with and without self-monitoring of VKA therapy ( $p=0.3624)$ and with and without artificial heart valve replacement $(p=0.3937)$ and with or without atrial fibrillation (0.0915) (- Table 5).

Table 4 Definition of grades of recommendation to continue or to change type of anticoagulant

\begin{tabular}{|c|c|c|c|c|c|c|}
\hline \multirow{2}{*}{$\begin{array}{l}\begin{array}{l}\text { Grade of } \\
\text { recommendation }\end{array} \\
\text { Strength of } \\
\text { recommendation }\end{array}$} & \multicolumn{2}{|l|}{$\begin{array}{l}\text { Continue } \\
\text { therapy }\end{array}$} & \multirow{2}{*}{$\begin{array}{l}\text { No } \\
\text { recommendation } \\
\begin{array}{l}\text { Not } \\
\text { defined }\end{array}\end{array}$} & \multicolumn{2}{|l|}{$\begin{array}{l}\text { Change } \\
\text { therapy }\end{array}$} & \multirow[t]{2}{*}{ Sum } \\
\hline & Strong & Moderate & & Moderate & Strong & \\
\hline \multicolumn{7}{|c|}{ Group 1: replies in study } \\
\hline$n$ & 340 & 235 & 20 & 73 & 22 & 690 \\
\hline$\%$ & 49.27 & 34.06 & 2.90 & 10.58 & 3.19 & 100 \\
\hline Term & $\begin{array}{l}-4.6500 \text { to } \\
-2.2292\end{array}$ & $\begin{array}{l}-2.1600 \text { to } \\
-0.2110\end{array}$ & $\begin{array}{l}-0.1776 \text { to } \\
0.1802\end{array}$ & $\begin{array}{l}0.2100 \text { to } \\
2.1860\end{array}$ & $\begin{array}{l}2.2192 \text { to } \\
3.9460\end{array}$ & na \\
\hline \multicolumn{7}{|c|}{ Group 2: replies in study } \\
\hline$n$ & 147 & 7 & 0 & 1 & 0 & 155 \\
\hline$\%$ & 94.84 & 4.52 & 0 & 0.64 & 0 & 100 \\
\hline Term & $\begin{array}{l}-7.4184 \text { to } \\
-2.3170\end{array}$ & $\begin{array}{l}-1.9312 \text { to } \\
-0.2610\end{array}$ & na & 0.4476 & na & na \\
\hline \multicolumn{7}{|c|}{ Group 3: replies in study } \\
\hline$n$ & 10 & 104 & 12 & 11 & 0 & 137 \\
\hline$\%$ & 7.30 & 75.91 & 8.76 & 8.03 & 0 & 100 \\
\hline Term & $\begin{array}{l}-2.9910 \text { to } \\
-2.2873\end{array}$ & $\begin{array}{l}-2.1895 \text { to } \\
-0.2368\end{array}$ & $\begin{array}{l}-0.1594 \text { to } \\
0.1962\end{array}$ & $\begin{array}{l}0.3028 \text { to } \\
1.3468\end{array}$ & na & na \\
\hline Score & $1 \mathrm{~A}$ & $1 \mathrm{~B}$ & 2 & $3 B$ & $3 \mathrm{~A}$ & \\
\hline
\end{tabular}



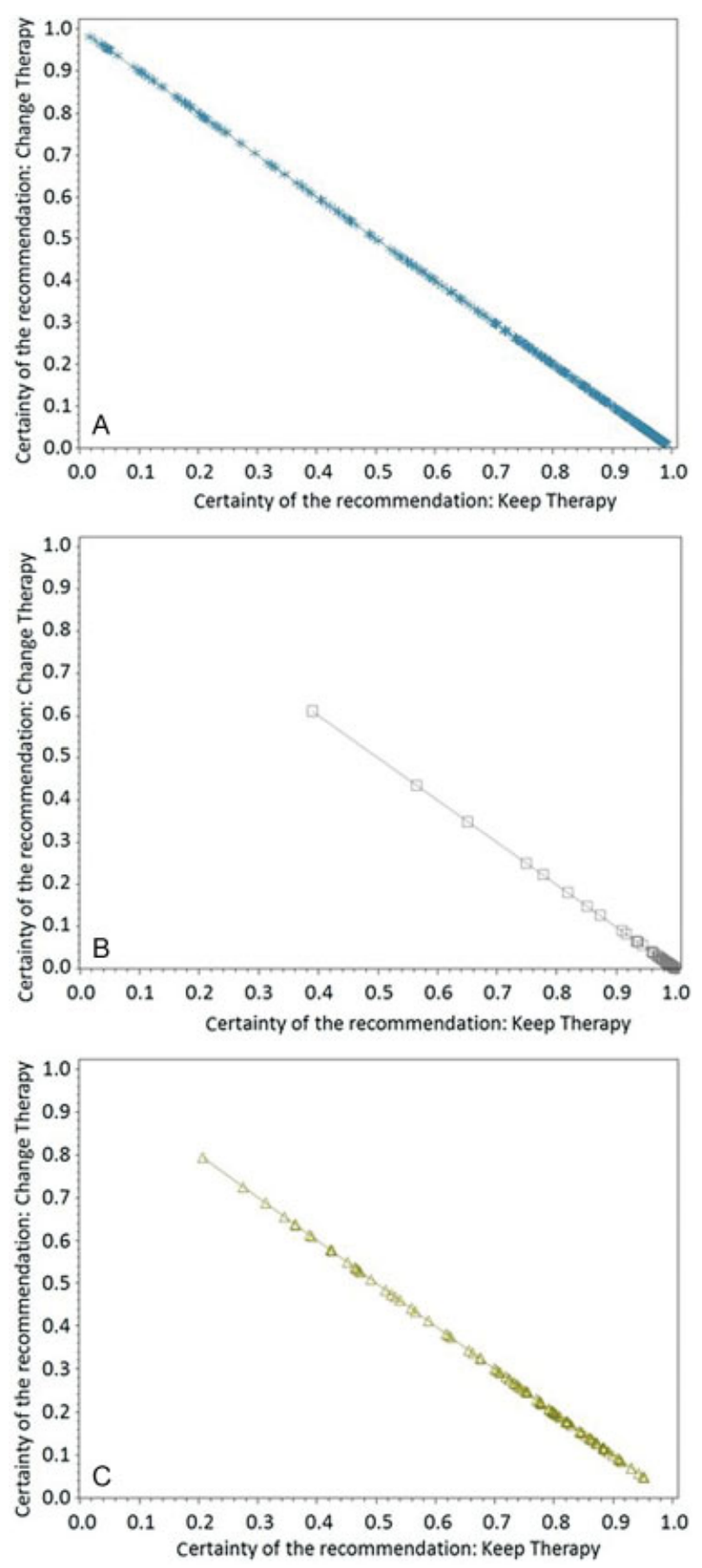

Fig. 3 The distribution of the strength of recommendations is shown (y-axis, to change therapy of currently used type of anticoagulant; $x$ axis, continue therapy with current type of anticoagulant) according to the replies of the patients of group 1 (A), group 2 (B), and group 3 (C) using the four significant statements of the questionnaire.

\section{Discussion}

In this study, we have shown how a simple questionnairebased tool can supports recommendations as to continue or to change the presently used type of oral anticoagulant based on the identification of patients' values and preferences.

The present investigation describes recommendations for the use of one of the two types of anticoagulants-VKA or NOAC-available today for AC of patients with nonvalvular atrial fibrillation and VTE based on a questionnaire for patients. The concept of categories and strengths of recommendations were taken from earlier publications. ${ }^{26}$ Recommendations were divided into strong and moderate type and into the grades to continue or to change type of anticoagulant or no specific recommendation for continuation of anticoagulant therapy resulting in five categories. For group 1 continuing therapy with VKA was more frequently recommended than in other groups. The recommendations for group 2 are also of specific importance because patients had actively changed AC from VKA to NOAC and a strong recommendation to change back to VKA would have had a relevant negative impact on the relevance of our questionnaire.

The questionnaire described here may be used for patients already receiving oral anticoagulant therapy but has not yet been adopted for patients before starting oral anticoagulant treatment. The results also indicate that patients with selfmonitoring of anticoagulant therapy may benefit from this questionnaire. Interestingly, the questionnaire did not show relevant differences of the replies if patients did or did not have artificial heart valve replacement therapy. These results are unexpected because NOAC are not approved for this indication based on unfavorable results of clinical studies. ${ }^{27}$ It may be argued that some of these patients would prefer NOAC therapy, a fact which was unknown so far. The usefulness of the questionnaire is supported by these subanalyses because the results may give insights into the wishes of patients which type of anticoagulant they prefer independently of the current type of AC and approval status of NOAC. Another interesting finding in the study is that patients who had decided to change AC from VKA to NOAC did not receive a strong recommendation to change the type of anticoagulant back to VKA. If some patients of these two groups would have been given a strong recommendation the value of the statements of the questionnaire would have been challenged.

Therapy with VKA was reported to be improved when clinical variables such as age, body weight, renal, and hepatic function, and potential drug interactions, bleeding or thrombotic complications during anticoagulant therapy, unstable INR-values or frequent missing of visits to determine INR values, are taken into account by the treating physician when selecting warfarin or an NOAC for initiation or changing anticoagulant therapy. ${ }^{28}$ Instable INR-values were considered to be relevant to improve adherence to therapy by including patients' preference for a therapy. A score was developed to characterize the knowledge of patients on anticoagulant therapy to improve self-monitoring of anticoagulant therapy. ${ }^{29}$ The daily costs of NOAC play an important role for the preference of patients compared with VKA. ${ }^{30}$ In some countries including Germany, the insurance companies take over the daily costs of NOAC in approved indications if patients fulfill some specific criteria regarding occurrence of side effects to VKA, variable INR values, high risk factors for thromboembolic events or bleeding complications or other criteria. ${ }^{31-34}$ The extent of reduction in the risk of stroke was given a higher relevance compared with the reduction of the risk of bleeding during treatment with VKA by patients in contrast to treating 
Table 5 Results of subanalysis: distribution of recommendations for patients with self-management of INR or conventional control of INR and with or without artificial heart valve replacement

\begin{tabular}{|c|c|c|c|c|c|c|}
\hline \multirow{2}{*}{$\begin{array}{l}\text { Grade of } \\
\text { recommendation } \\
\text { Strength of } \\
\text { recommendation }\end{array}$} & \multicolumn{2}{|l|}{$\begin{array}{l}\text { Continue } \\
\text { therapy }\end{array}$} & \multirow{2}{*}{$\begin{array}{l}\text { No } \\
\text { recommendation } \\
\text { Not defined }\end{array}$} & \multicolumn{2}{|l|}{$\begin{array}{l}\text { Change } \\
\text { therapy }\end{array}$} & \multirow[t]{2}{*}{ Sum } \\
\hline & Strong & Moderate & & Moderate & Strong & \\
\hline \multicolumn{7}{|c|}{ Self-management of INR } \\
\hline$n$ & 134 & 84 & 7 & 27 & 10 & 262 \\
\hline$\%$ & 51.1 & 32.1 & 2.7 & 10.3 & 3.8 & 100 \\
\hline Term & $\begin{array}{l}-4.6516 \text { to } \\
-2.2468\end{array}$ & $\begin{array}{l}-2.1616 \text { to } \\
-0.3102\end{array}$ & -0.1632 to 0.1786 & $\begin{array}{l}0.2200 \text { to } \\
2.1844\end{array}$ & $\begin{array}{l}2.9290 \text { to } \\
3.9444\end{array}$ & - \\
\hline \multicolumn{7}{|c|}{ Conventional INR control } \\
\hline$n$ & 206 & 151 & 13 & 46 & 12 & 428 \\
\hline$\%$ & 48.1 & 35.3 & 3.0 & 10.8 & 2.8 & 100 \\
\hline Term & $\begin{array}{l}-4.6516 \text { to } \\
-2.2308\end{array}$ & $\begin{array}{l}-2.1616 \text { to } \\
-0.2126\end{array}$ & -0.1792 to 0.1726 & $\begin{array}{l}0.2084 \text { to } \\
2.1844\end{array}$ & $\begin{array}{l}2.2176 \text { to } \\
3.9444\end{array}$ & - \\
\hline \multicolumn{7}{|c|}{ Heart valve replacement } \\
\hline$n$ & 56 & 34 & 6 & 9 & 2 & 107 \\
\hline$\%$ & 52.3 & 31.8 & 5.6 & 8.4 & 1.9 & 100 \\
\hline Term & $\begin{array}{l}-4.6516 \text { to } \\
-2.2934\end{array}$ & $\begin{array}{l}-2.1616 \text { to } \\
-0.3870\end{array}$ & -0.1632 to 0.1786 & $\begin{array}{l}0.4376 \text { to } \\
2.1844\end{array}$ & $\begin{array}{l}3.2564 \text { to } \\
3.2564\end{array}$ & - \\
\hline \multicolumn{7}{|c|}{ No heart valve replacement } \\
\hline$n$ & 284 & 201 & 14 & 64 & 20 & 583 \\
\hline$\%$ & 48.7 & 34.5 & 2.4 & 11.0 & 3.4 & 100 \\
\hline Term & $\begin{array}{l}-4.6516 \text { to } \\
-2.2308\end{array}$ & $\begin{array}{l}-2.1616 \text { to } \\
-0.2126\end{array}$ & $\begin{array}{l}-0.1792 \text { to } \\
0.1726\end{array}$ & $\begin{array}{l}0.2084 \text { to } \\
2.1844\end{array}$ & $\begin{array}{l}2.2176 \text { to } \\
3.9444\end{array}$ & - \\
\hline \multicolumn{7}{|c|}{ None atrial fibrillation } \\
\hline$n$ & 159 & 112 & 12 & 31 & 13 & 327 \\
\hline$\%$ & 48.62 & 34.25 & 3.669 & 9.48 & 3.975 & 100 \\
\hline Term & $\begin{array}{l}-4.6500 \text { to } \\
-2.2292\end{array}$ & $\begin{array}{l}-2.1600 \text { to } \\
-0.2142\end{array}$ & $\begin{array}{l}-0.1616 \text { to } \\
0.1802\end{array}$ & $\begin{array}{l}0.2100 \text { to } \\
2.1860\end{array}$ & $\begin{array}{l}2.2192 \text { to } \\
3.9460\end{array}$ & - \\
\hline \multicolumn{7}{|l|}{ Atrial fibrillation } \\
\hline$n$ & 181 & 123 & 8 & 42 & 9 & 363 \\
\hline$\%$ & 49.86 & 33.88 & 2.20 & 11.57 & 2.479 & 100 \\
\hline Term & $\begin{array}{l}-4.6500 \text { to } \\
-2.2714\end{array}$ & $\begin{array}{l}-2.1600 \text { to } \\
-0.2110\end{array}$ & -0.1776 to 0.1742 & $\begin{array}{l}0.2216 \text { to } \\
2.1860\end{array}$ & $\begin{array}{l}2.3090 \text { to } \\
3.9460\end{array}$ & - \\
\hline
\end{tabular}

physicians. This indicates to include the opinion of patients when deciding which anticoagulant to use. ${ }^{35}$

Some limitations of the study have to be taken into account. Patients with NOAC therapy were included into the study though they do not participate in focus groups in contrast to patients treated with VKA. Patients with psychiatric diseases may not be able to use the questionnaire. Depressiveness has a negative impact on the time in therapeutic range of the INR during therapy with VKA compared with not patients without depressiveness. ${ }^{36} \mathrm{~A}$ restriction for use of NOAC is the current lack of a specific antidote. ${ }^{30}$ At the time of drafting the original questionnaire this topic was not discussed in the focus group patients and was therefore not included. ${ }^{15}$ Some specific groups of patients were included into the study despite the known fact that they expose a higher confidence with VKA if self-monitoring of therapy is performed or that an indication such as artificial heart valve replacement is not approved for NOAC. The data of the group of NOAC naive patients and of patients with self-monitoring and artificial heart valve replacement further supported the usefulness of the questionnaire to identify the preference of patients for one of the two types of oral anticoagulants. It remains open if the questionnaire is useful for patients before initiation of anticoagulant therapy. Our study cohort was also not ethnically diverse. Further studies in different ethnic groups and clinical settings (e.g., inpatients vs. outpatients) may be necessary.

In conclusion, the present investigation describes the usefulness of four statements to identify the preference of 
patients on oral AC for one of the two classes of currently available oral anticoagulants-VKA or NOAC. This is the first tool to aid this decision on the base of the patients' own opinion. The transcultural use of the questionnaire remains to be explored. We suggest that this questionnaire can be introduced easily into the daily clinical practice due to its sensitivity to measure the preference of patients for the type of anticoagulant to be used. Future perspectives include the use of telemedicine techniques ${ }^{37}$ to ease the availability of the questionnaire for patients and health care staff.

\section{Conflict of Interest}

J. H.: Lecturing and consulting fees from Novartis, Bayer HealthCare, Boehringer Ingelheim, Roche Diagnostics, Pfizer, Bristol-Myers Squibb, Daichii-Sankyo, LEO Pharma, support of research from Novartis, Bayer HealthCare, Boehringer Ingelheim, Roche Diagnostics, Pfizer, BristolMyers Squibb, HepLabs.

M.W. was employed by AstraZeneca R\&D, Mölndal, as director of discovery medicine (equivalent to translational medicine) from 2003 to 2006, while on sabbatical leave from his professorship at the University of Heidelberg. Since returning to this position in January 2007, he has received lecturing and consulting fees from Sanofi-Aventis, Bayer, Boehringer-Ingelheim, Novartis, Takeda, Roche, Pfizer, Bristol-Myers, Daichii-Sankyo, Lilly, Novo-Nordisk, Shire, and LEO Pharma.

G. L.: Consultant for Bayer, Merck, Sanofi, BMS/Pfizer, Daiichi-Sankyo, Biotronik, Medtronic, Portola, and Boehringer Ingelheim and has been on the speakers bureau for Bayer, BMS/Pfizer, Boehringer Ingelheim, Daiichi-Sankyo, Medtronic.

The other authors do not have to declare any conflict of interest.

\section{Acknowledgment}

The authors gratefully acknowledge the cooperation of the study teams of the participating centers.

\section{References}

1 Falck-Ytter Y, Francis CW, Johanson NA, et al; American College of Chest Physicians. Prevention of VTE in orthopedic surgery patients: Antithrombotic Therapy and Prevention of Thrombosis, 9th ed: American College of Chest Physicians EvidenceBased Clinical Practice Guidelines. Chest 2012;141(2, Suppl): e278S-e325S

2 Vílchez JA, Gallego P, Lip GY. Safety of new oral anticoagulant drugs: a perspective. Ther Adv Drug Saf 2014; $5(1): 8-20$

3 Ogilvie IM, Newton N, Welner SA, Cowell W, Lip GY. Underuse of oral anticoagulants in atrial fibrillation: a systematic review. Am J Med 2010;123(7):638-645.e4

4 Hong C, Kim S, Curnew G, Schulman S, Pullenayegum E, Holbrook A. Validation of a patient decision aid for choosing between dabigatran and warfarin for atrial fibrillation. J Popul Ther Clin Pharmacol 2013;20(3):e229-e237
5 Howitt A, Armstrong D. Implementing evidence based medicine in general practice: audit and qualitative study of antithrombotic treatment for atrial fibrillation. BMJ 1999;318(7194):1324-1327

6 Thomson RG, Eccles MP, Steen IN, et al. A patient decision aid to support shared decision-making on anti-thrombotic treatment of patients with atrial fibrillation: randomised controlled trial. Qual Saf Health Care 2007;16(3):216-223

7 Zeber JE, Manias E, Williams AF, et al; ISPOR Medication Adherence Good Research Practices Working Group. A systematic literature review of psychosocial and behavioral factors associated with initial medication adherence: a report of the ISPOR medication adherence \& persistence special interest group. Value Health 2013; 16(5):891-900

8 Camm AJ, Lip GY, De Caterina R, et al; ESC Committee for Practice Guidelines-CPG; Document Reviewers. 2012 focused update of the ESC Guidelines for the management of atrial fibrillation: an update of the 2010 ESC Guidelines for the management of atrial fibrillation-developed with the special contribution of the European Heart Rhythm Association. Europace 2012;14(10):1385-1413

9 Anderson JL, Halperin JL, Albert NM, et al. Management of patients with atrial fibrillation (compilation of 2006 ACCF/AHA/ESC and 2011 ACCF/AHA/HRS recommendations): a report of the American College of Cardiology/American Heart Association Task Force on Practice Guidelines. J Am Coll Cardiol 2013;61(18):1935-1944

10 MacLean S, Mulla S, Akl EA, et al; American College of Chest Physicians. Patient values and preferences in decision making for antithrombotic therapy: a systematic review: Antithrombotic Therapy and Prevention of Thrombosis, 9th ed: American College of Chest Physicians Evidence-Based Clinical Practice Guidelines. Chest 2012;141(2, Suppl):e1S-e23S

11 National-Institute-for-Health-and-Care-Excellence. Atrial fibrillation: the management of atrial fibrillation. (Clinical guideline 180) 2014. Available at: http://guidance.nice.org.uk/CG180. Accessed February 6, 2015

12 Farin E, Meder M. Personality and the physician-patient relationship as predictors of quality of life of cardiac patients after rehabilitation. Health Qual Life Outcomes 2010;8:100

13 Gabbidon J, Brohan E, Clement S, Henderson RC, Thornicroft G; MIRIAD Study Group. The development and validation of the Questionnaire on Anticipated Discrimination (QUAD). BMC Psychiatry 2013;13(1):297

14 Moia M, Mantovani LG, Carpenedo M, et al. Patient preferences and willingness to pay for different options of anticoagulant therapy. Intern Emerg Med 2013;8(3):237-243

15 Zolfaghari S, Harenberg J, Froelich L, Wehling M, Weiss C. Development of a tool to identify patients' preference for vitamin $\mathrm{K}$ antagonist or direct oral anticoagulant therapy. Semin Thromb Hemost 2014;40(1):121-128

16 Elewa HF, DeRemer CE, Keller K, Gujral J, Joshua TV. Patients satisfaction with warfarin and willingness to switch to dabigatran: a patient survey. J Thromb Thrombolysis 2014;38(1):115-120

17 Zolfaghari S, Harenberg J, Knäble H, et al. Investigation on motivation of patients to participate in clinical studies with new oral anticoagulants (abstract). Haemostaseologie 2013;33(1):5-22

18 Crawford B, Stanford RH, Wong AY, Dalal AA, Bayliss MS. Development of a questionnaire to assess experience and preference of intranasal corticosteroids in patients with allergic rhinitis. Patient Relat Outcome Meas 2011;2:119-126

19 Franke GH. [Possibilities of computer-assisted administration of the revised Freiburg Personality Inventory. 2 experimental studies]. Zeitschrift fur experimentelle Psychologie. Organ der Deutschen Gesellschaft fur Psychologie 1997;44(2):332-356

20 Forgays DG, Forgays DK, Spielberger CD. Factor structure of the StateTrait Anger Expression Inventory. J Pers Assess 1997;69(3):497-507

21 Fisher PL, Durham RC. Recovery rates in generalized anxiety disorder following psychological therapy: an analysis of clinically significant change in the STAI-T across outcome studies since 1990. Psychol Med 1999;29(6):1425-1434 
22 Völler H, Taborski U, Dovifat C, et al. ProTime self-management yielding improvement of fluency and quality of life. Thromb Haemost 2007;98(4):889-895

23 Oechsner W, Geiler S, Huber-Lang M. The impact of a dedicated training program for oral examiners at a medical school in Germany: a survey among participants from operative and nonoperative disciplines. Patient Saf Surg 2013;7(1):22

24 EvaSys. Available at: http://www.evasys.de/startseite.html. Accessed May 28, 2014

25 Skogen JC, Bøe T, Knudsen AK, Hysing M. Psychometric properties and concurrent validity of the CRAFFT among Norwegian adolescents. Ung@hordaland, a population-based study. Addict Behav 2013;38(10):2500-2505

26 Guyatt GH, Norris SL, Schulman S, et al; American College of Chest Physicians. Methodology for the development of antithrombotic therapy and prevention of thrombosis guidelines: Antithrombotic Therapy and Prevention of Thrombosis, 9th ed: American College of Chest Physicians Evidence-Based Clinical Practice Guidelines. Chest 2012;141(2, Suppl):53S-70S

27 Eikelboom JW, Connolly SJ, Brueckmann M, et al; RE-ALIGN Investigators. Dabigatran versus warfarin in patients with mechanical heart valves. N Engl J Med 2013;369(13):1206-1214

28 Lu Y, Branstad R, Karim RM, Asinger RW. Consideration of clinical variables for choosing new anticoagulant alternatives to warfarin for the management of non-valvular atrial fibrillation.J Clin Pharm Ther 2014;39(6):628-636

29 Chenot JF, Hua TD, Abu Abed M, et al. Safety relevant knowledge of orally anticoagulated patients without self-monitoring: a baseline survey in primary care. BMC Fam Pract 2014;15:104
30 Ghijben P, Lancsar E, Zavarsek S. Preferences for oral anticoagulants in atrial fibrillation: a best-best discrete choice experiment. Pharmacoeconomics 2014;32(11):1115-1127

31 Chorão P, Pereira AM, Fonseca JA. Inhaler devices in asthma and COPD-an assessment of inhaler technique and patient preferences. Respir Med 2014;108(7):968-975

32 Sylwestrzak G, Liu J, Stephenson JJ, Ruggieri AP, DeVries A. Considering patient preferences when selecting anti-tumor necrosis factor therapeutic options. Am Health Drug Benefits 2014;7(2):71-81

33 Demary W, Schwenke H, Rockwitz K, et al. Subcutaneously administered methotrexate for rheumatoid arthritis, by prefilled syringes versus prefilled pens: patient preference and comparison of the self-injection experience. Patient Prefer Adherence 2014; 8:1061-1071

34 Tinelli M, Nikoloski Z, Kumpunen S, et al. Decision-making criteria among European patients: exploring patient preferences for primary care services. Eur J Public Health 2014

35 Devereaux PJ, Anderson DR, Gardner MJ, et al. Differences between perspectives of physicians and patients on anticoagulation in patients with atrial fibrillation: observational study. BMJ 2001; 323(7323):1218-1222

36 Michal M, Prochaska JH, Ullmann A, et al. Relevance of depression for anticoagulation management in a routine medical care setting: results from the ThrombEVAL study program. J Thromb Haemost 2014;12(12):2024-2033

37 Prochaska JH, Coldewey M, Göbel S, et al; for the thrombEVAL Study Group. Evaluation of oral anticoagulation therapy: rationale and design of the thrombEVAL study programme. Eur J Prev Cardiol 2014 